\title{
Em meus olhos e ouvidos: música popular, deslocamento no espaço urbano e a produção de sentidos em lugares dos Beatles
}

\author{
In my eyes and ears: \\ popular music, displacement in urban space and the \\ creation of meaning in places of The Beatles \\ Luís Henrique Assis Garcia
}

\begin{abstract}
Abordando os músicos populares como citadinos, meu propósito é investigar formas adotadas por eles para articular as relações entre música e espaço urbano. É possível divisar formas de criar a música popular que revelam tanto os lugares - traduzidos em evocações de sons, imagens, personagens, cenários, ex-
\end{abstract}

Este artigo beneficiou-se de discussões realizadas no Centro de Convergência de Novas Mídias (CCNM) da Universidade Federal de Minas Gerais (UFMG) e no Mestrado em Gestão Integrada do Território da Universidade Vale do Rio Doce (UNIVALE), entre 2009 e 2010.

Luiz Henrique Assis Garcia é mestre e doutor em História pela Faculdade de Filosofia e Ciências Humanas da UFMG e professor e pesquisador da Escola de Ciência da Informação da UFMG, Belo Horizonte, Brasil (luhen_asgar@yahoo.com.br).

Artigo recebido em 31 de dezembro de 2010 e aprovado para publicação em 29 de março de 2011.

Est. Hist., Rio de Faneiro, vol. 24, no 47, p. 99-118, janeiro-junho de 2011. 
pressões de uso cotidiano ou gêneros musicais que lhes são vinculados - quanto os elementos presentes na canção que constituem traços significativos da experiência social e histórica dos músicos na cidade. Isso implica compreender como a música participa da construção e da negociação de identidades que definem vínculos e fronteiras no tecido urbano, ao mesmo tempo em que evidencia as trajetórias traçadas pelos músicos que o atravessam. Desse modo, é possível perceber seu papel nas trocas e nos embates que marcam a elaboração de sentidos atribuídos a grupos e lugares (Stokes, 1996: 4).

Optei pela realização de um estudo de caso, uma vez que a proposta é discutir o papel desempenhado pela música na maneira em que se vive na cidade $\mathrm{e}$ nos modos particulares de se imaginar e atribuir significado ao ambiente urbano, a partir de uma análise pormenorizada de gravações selecionadas e de fontes que permitam captar elementos referentes à experiência dos músicos que as realizaram. Com esse intuito, foram escolhidas duas canções dos Beatles, Strawberry Fields Forever e Penny Lane, ${ }^{1}$ lançadas em compacto simples ${ }^{2}$ de duplo lado $\mathrm{A}^{3} \mathrm{em}$ 17 de fevereiro de 1967. As duas canções remetem, cada uma a seu modo, a lugares de Liverpool, cidade natal de seus compositores, e costumam ser citadas em discussões sobre

(...) como a música constrói ou é usada para representar um lugar, sendo um exemplo disso a forma como os Beatles atribuíram sentido a lugares e significados musicais associados através de canções como Penny Lane ou Strawberry Fields Forever, as quais, por sua vez, têm impacto em como as pessoas compreendem estes lugares (Negus, 1996: 185)

De fato, há vários trabalhos que se debruçam sobre elas, com enfoques que vão da geografia cultural (Kruse II, 2005; Daniels, 2006) aos estudos acadêmicos de música popular (Barna, 2010), passando por ensaios de crítica musical, como os de MacDonald (1995) e Pollack (1995). Se os ensaios oferecem uma análise acurada dos aspectos sonoros, com o mérito de não recair em excessivo formalismo, os demais trabalhos dedicam seus maiores esforços a mostrar como a formulação de identidades através da música associa representações do passado e da localidade, articuladas em um contexto histórico e cultural mais amplo. Esses textos não descuidam da análise dos aspectos musicais. O de Daniels, em particular, é bem-sucedido ao fazê-lo, principalmente porque não perde de vista as condições de produção e consumo da música popular.

Minha contribuição certamente segue essa trilha, mas confere ainda mais atenção à sonoridade e às práticas dos músicos populares, considerando 
discos e gravações como documentos históricos, postura que venho adotando em minhas pesquisas (Garcia, 2003; 2007). Isso implicou incluir na pesquisa realizada outros registros, além das faixas que foram efetivamente lançadas, e principalmente pensar não apenas como as canções remetiam a paisagens, valores ou mitos a elas associados, mas como as gravações são construídas como quadros sonoros que produzem um sentido de lugar.

Partindo dessa observação, proponho uma análise conduzida em dois momentos. O primeiro toma como ponto de partida as trajetórias e memórias dos músicos, articulando elementos biográficos e identidades construídas em sua experiência social e histórica como citadinos, tanto em seu passado (Liverpool), quanto no presente de então (Londres). A intenção é mostrá-las como referências utilizadas para a criação das composições e elaboração dos arranjos. $\mathrm{O}$ segundo trata mais diretamente das canções, procurando perceber uma construção do "lugar" que passa pela incorporação de referências ao espaço e à experiência urbana nas gravações. De acordo com a concepção de música popular aqui adotada, que identifica sua emergência e consolidação às transformações próprias da modernidade - como a urbanização, a presença das massas na cidade e a introdução dos meios massivos de comunicação e da indústria cultural -, também será preciso tecer aí algumas considerações sobre o contexto de produção e recepção do compacto.

\section{Trajetórias, memórias: os Beatles como citadinos}

Em 1966 os Beatles tiveram um ano turbulento. No auge da chamada beatlemania, excursionando por várias partes do mundo, eles enfrentaram a ira de conservadores no Japão por tocar no Budokan, considerado um templo sagrado das artes marciais. Foram atacados por uma multidão nas Filipinas, em virtude do "incidente diplomático" causado ao ignorarem, acidentalmente, o convite da primeiora-dama Imelda Marcos, esposa do ditador Ferdinand Marcos, para uma festa de recepção oficial. Estiveram no centro de uma controvérsia religiosa nos Estados Unidos, em função das declarações de John Lennon de que os Beatles seriam "mais populares do que Jesus Cristo", o que lhes rendeu ameaças de morte da Ku Klux Klan e fogueiras em praças públicas em alguns estados americanos, consumindo a "parafernália" beatle. E quando decidiram encerrar definitivamente suas apresentações ao vivo, em agosto, surgiram rumores sobre a separação do grupo. Era cada vez mais difícil ser um beatle (Kozinn, 1995: 145-147).

De fato eles se separaram temporariamente, mas se reuniram em Londres em 24 de novembro para iniciar as gravações de seu próximo LP, que viria a 
ser Sgt. Pepper's Lonely Hearts Club Band. As sessões começaram com uma canção que Lennon começara a compor ${ }^{4}$ na Espanha, enquanto fazia o papel de um soldado no filme anti-belicista de Richard Lester, How I won the war. Seu título era Strawberry Fields Forever, inspirado no nome deum solar vitoriano com amplos jardins, que, segundo seu autor,

(...) É um nome, um ótimo nome (...) estávamos tentando escrever sobre Liverpool e eu simplesmente listei todos os nomes que soavam bem (...) era um lugar perto de casa em que funcionava um lar do Exército da Salvação. [No entanto, ele acrescenta imediatamente que] (...) tenho visões de Strawberry Fields (...) é qualquer lugar aonde você queira ir. ${ }^{5}$

Na mesma entrevista, Lennon menciona que já tentara escrever sobre sua cidade natal em In my life, ${ }^{6}$ inspirado pela pergunta de um jornalista sobre a possibilidade de usar algo de sua infância nas músicas (Daniels, 2006: 35; Heylin, 2007: 59). Paul McCartney, por sua vez, compôs Penny Lane (que apresentou aos outros Beatles em 29 de dezembro), instigado justamente pela canção com a qual viria a fazer par e se equiparar, dentro de um esquema de colaboração que incluía uma boa dose de rivalidade, como atestaram posteriormente $o$ produtor dos Beatles, George Martin, e o próprio McCartney (Heylin, 2007: 65). Tratando da alameda homônima, ${ }^{7}$ era "um retrato mais prosaico da Liverpool de sua juventude", ou, como o próprio compositor diria, “em parte é real, em parte saudade de um lugar que é ótimo - céus azuis suburbanos de que nos lembramos" (Heylin, 2007: 68). Essa lembrança é composta por imagens, entrepostas e condensadas de modo seletivo, como uma operação da memória (Barna, 2010: 51).

Como afirma Daniels, "os nomes dos dois lugares eram pontos-chave no processo de ordenar os mundos da infância de Lennon e McCartney" (Daniels, 2006: 37). Assim, enquanto os Beatles buscavam se distanciar da sua imagem de Fab Four, recorriam à de "os quatro rapazes de Liverpool", traçando planos para um disco que, a princípio, pretendia ser uma coleção temática de canções nostálgicas sobre o norte da Inglaterra. Essa preocupação com o passado e a volta às raízes era ressaltada no uso de expressões de sabor local como " $a$ four of fish" (um prato feito de peixe com batatas que custava quatro centavos), ${ }^{8}$ em Penny Lane, ou nos primeiros esboços em voz e violão de Strawberry Fields Forever (então provisoriamente intitulada It's not too bad), num formato que remete às baladas folk, quando o refrão ainda dizia "Let me take you back" ("Deixe-me levá-lo de volta"). ${ }^{9}$ 
Esse elemento biográfico pode ser situado num contexto mais amplo, a partir da discussão feita por Raphael Samuel sobre as ressignificações do passado na sociedade britânica. $\mathrm{O}$ autor identifica, marcadamente a partir da segunda metade do século XX, o "entusiasmo ressuscitador" que tomou conta de vários aspectos da vida social, da decoração de interiores ao consumo de antiguidades, da difusão do gosto por fotografias antigas à historicização do ambiente construído (Samuel, 1994). Essa perspectiva também influenciava o cenário da música popular. Ao discutir o conceito de patrimônio (heritage) em suas múltiplas acepções, Samuel chama atenção para o revivalismo da canção folk, vista como patrimônio a ser preservado, e sua conexão com o Skiffle, gênero popular que era uma combinação "faça você mesmo" de jazz, folk e canções de trabalho, que virou moda no final dos anos 1950 (Samuel, 1994: 206). Era justamente o que tocavam, além de rock ' $n$ ' roll, os Quarry Men, primeira banda formada por John em Liverpool, à qual Paul acabaria se juntando em 1957 (Kozzin, 1995: 20-21).

Essa nova visão de história, certamente mais democrática, favoreceu a construção de uma "britanicidade" urbana, que envolvia o culto à vila interiorana dos "bons velhos tempos" e trazia o retorno de representações sobre a paisagem pastoral, agora conectada ao cenário suburbano, vistas como índices das peculiaridades inglesas. Segundo Daniels, a sensibilidade suburbana, incorporando o pastoral, ocupou papel central na cultura pop inglesa no início dos anos 1960, fosse como lugar de tédio e respeitabilidade doméstica do qual fugir, fosse como lugar de uma infância idílica ao qual retornar (Daniels, 2006: 31). Alguns autores percebem aí a construção de uma "identidade inglesa" (Englishness), "(...) associada aos sons de Mersey [região onde se localiza Liverpool] dos Beatles (...) [na qual] imagens nostálgicas de cidade pequena e de vida da classe trabalhadora suburbana assentaram a música em locais específicos" (Connell \& Gibson, 2002: 125).

Essa colocação remete-nos ao tema do relacionamento entre o espaço, a música popular e a construção de identidades, seja de grupos sociais, étnicos, seja de gêneros, gerações ou nações. Nesse sentido não me parece certo pensar, como faz Barna (2010: 50), que valores culturais localizados são reforçados, transmitidos ou comentados nas canções, a despeito dos efeitos "globalizantes" dos meios massivos, pois sua própria gestação depende de trânsitos e negociações mediados por eles. Tais relações, portanto, são historicamente constitutivas da indústria e do mercado fonográficos. De uma perspectiva antropológica, Bastos destaca a emergência da música popular como "fenômeno global" e elemento integrante da produção de identidades nacionais, mas pensada dentro de um quadro marcado por um intenso intercâmbio de gêneros e autores: 
(...) o maxixe dialoga com o tango, que conversa com a habanera, que proseia com o blues, com o foxtrote, (...) num processo de diálogo no qual a delimitação de fronteiras atende simultaneamente às setas contrastiva e inclusiva. (...) [e] o diálogo, em vez de dissolver, o que faz é exatamente constituir os interlocutores como outros entre si (...) (Bastos, 1996: 175)

Nos estudos que vêm tratando das relações entre música popular, identidade e lugar, destaca-se a preocupação em compreender esses diálogos (Stokes, 1994; Negus, 1996; Connell e Gibson, 2002). Em seu trabalho sobre "o som de Liverpool", Sarah Cohen (1994) investiga as relações entre a cidade e sua música a partir da premissa de que "a noção de som local (...) reflete o desejo de afirmar simbolicamente a diferença e um sentido de identidade local" (Cohen, 1994: 129). Daí ela atentar para particularidades como a influência da presença irlandesa, dos coros religiosos, da organização da cena local e da área portuária, elementos considerados importantes para a identidade da cidade (Cohen, 1994: 119, 121 e 128). As cidades portuárias

(...) tornaram-se lugares de onde se diz que "sons" particulares emergiram. Os portos foram importantes articulações de transporte, lugar de encontro para uma diversidade de migrantes, residentes e marinheiros (...) e pontos de distribuição para música importada (Connell \& Gibson, 2002: 103)

Aliás, a presença de elementos como porto, dificuldades econômicas e humor é recorrente em depoimentos dos Beatles, envolvendo memórias sobre sua cidade natal. Lennon, em uma entrevista dada em 1970, afirma que

[n]ão havia nada grande em Liverpool. Era muito pobre, uma cidade muito pobre, e dura. Mas as pessoas têm um senso de humor por que estão em tanto dissabor... É cosmopolitana, e é onde os marinheiros voltavam para casa com discos de blues da America nos navios (Kozinn, 1995: 15).

McCartney enfatizaria um sentido mais provinciano, embora compartilhando a visão de seu parceiro sobre a capacidade que seus moradores demonstram de enfrentar os reveses da vida: 
(...) Já rodei o mundo (...) Nunca conheci ninguém tão bom como algumas das pessoas que conheço de Liverpool que não são nada, que não fazem nada. Elas não são importantes ou famosas. Mas são espertas (...) pessoas que podem passar através dos problemas como faca quente através da manteiga. ${ }^{10}$

Em 1967, mesmo vivendo em Londres no auge da fama dos Beatles, sua auto-imagem deixava entrever o conflito entre provincianismo e cosmopolitismo resultante da experiência de deslocamento de Liverpool para a capital. George Harrison, naquele período, estava particularmente engajado em se distanciar da imagem de beatle, mas preferiu explorar mais profundamente suas ligações com a India (onde fora estudar cítara após o fim da turnê) e fugir da nostalgia, exercitando sua veia cáustica e experimental como compositor em Only a Northern Song ${ }^{11}$ (Apenas uma Canção do Norte), a primeira canção que apresentou durante as gravações do disco.

Ao mesmo tempo em que tinha uma atmosfera "desmontada", "desafinada", "desconstruída" em sua harmonia irregular (que a própria letra enuncia: "os acordes estão dando errado") e permeada por uma trilha com ruídos (Pollack, 1995: 578), era uma sátira envolvendo o nome da editora que controlava os direitos das composições dos Beatles, pois Harrison estava insatisfeito com as porcentagens que lhe cabiam. Mas pode também ter sido tomada como crítica indigesta ao conceito proposto para o LP, especialmente caro para Paul, que àquela altura já tinha elaborado a ideia da "banda de sopros eduardiana", tocando num parque em algum lugar do Norte para a canção homônima que abriria Sgt. Pepper's Lonely Hearts Club Band (Heylin, 2007: 110-111).

A viagem de George parecia tomar outra direção. Ele mesmo declarou a Hunter Davies, que então escrevia a biografia autorizada do grupo:

Por muito tempo não sabíamos que poderíamos fazer mais. Éramos apenas rapazes do norte que tinham permissão para fazer música nos grandes estúdios da EMI (...) (Heylin, 2007: 99).

Sendo assim, mesmo com muitas afinidades com as outras gravações em termos musicais, Only a Northern Song acabou sendo barrada do disco.

O livro de Davies iria exatamente enfatizar o período da juventude e mostrar como a parceria de Lennon e McCartney sustentava-se no solo comum do mundo suburbano que ambos haviam habitado. Daniels encarrega-se de desfazer as idealizações típicas de biografias autorizadas, apontando que, enquanto McCartney vivia em uma casa georgiana cheia de obras de arte no descolado St. 
John's Wood, próximo de Abbey Road ${ }^{12}$ e a um pulo de Bloomsbury (onde ficava a livraria Índica, ponto de encontro underground londrino), Lennon levava uma vida mais doméstica em Kenwood, mansão que imitava o estilo Tudor e ficava mais distante do centro, em Weybridge, Surrey.

Em entrevista posterior ao fim dos Beatles, Paul menciona que John se sentia restringido pela vida doméstica, enquanto ele circulava pelas rodas vanguardistas de Londres (Daniels, 2006: 36). John, por sua vez, falaria com mágoa sobre esse período, queixando-se de sua vida suburbana com a mulher e o filho enquanto Paul "agitava na cidade". ${ }^{13} \mathrm{O}$ quadro se completa com uma ponderação feita por Ringo Starr anos depois, levando em conta os filmes e as gravações caseiras que John fazia na época: "Sentia que Paul estava se misturando com uma turma pouco convencional, mas ele era muito convencional (...) enquanto John vinha sendo fora do convencional em casa" (Daniels, 2006: 36).

Assim, se as duas canções trazem referências explícitas a Liverpool, não se pode esquecer que são informadas igualmente pela experiência dos compositores como moradores de Londres, circulando e mantendo contato com a cena vanguardista da cidade. Mas tal constatação sugere considerar que a identidade com a terra natal também guardava relação com o espaço que cada um ocupara no ambiente urbano e na vida social. Muitos anos depois, ao rememorar Strawberry Fields como local de brincadeiras, Lennon também revisita a vida dos Beatles em Liverpool:

(...) é um lugar real. Depois que deixei de morar em Penny Lane, fui morar com minha tia que vivia no subúrbio, em uma boa casa geminada com um pequeno jardim, e médicos e advogados e gente assim vivendo nas redondezas... não aquele tipo de imagem do pobre esfarrapado que foi projetada em todas as histórias de Beatles. No sistema de classes, era por volta de meia classe acima de Paul, George e Ringo, que viviam em casas subsidiadas pelo governo. Tínhamos nossa própria casa e um jardim. Eles não tinham nada como aquilo. ${ }^{14}$

É possível perceber contrastes entre as visões que cada um expressava sobre ser do norte. Para Heylin, enquanto Lennon se preocupava em ressaltar o conflito de classes entre o trabalhador médio "do norte" e o sulista mimado, tomando partido das "pessoas desprezadas", Paul idealizou sua infância no norte, permitindo que ela agisse como contraponto ao dia-a-dia mundano da figura anti-heroica representada por John. A chave para entender o contexto em que as duas canções estudadas foram compostas e suas relações com a experiên- 
cia dos Beatles como citadinos pode estar na ambiguidade que caracteriza o conceito do LP que pretendiam gravar, em que a música deveria ser inovadora, mas as letras seriam nostálgicas, se bem que na prática o contrário também tenha ocorrido! É precisamente sobre essa prática que iremos nos debruçar a seguir.

\section{Campos de morango, alameda do centavo: sons e sentidos}

Seria de Lennon uma perspectiva mais realista, atada ao dia-a-dia, e de McCartney a atitude sonhadora, por vezes escapista? Vale ressaltar a complexidade e polissemia presente nas canções da dupla, pois tal contraste não é tão bem delimitado no par do compacto. Enquanto a composição de Lennon é introspectiva, vacilante e instala uma atmosfera onírica, a de McCartney é uma descrição vívida e detalhada de um lugar público, percorrida e percebida por um narrador de sentidos atentos, cronista do prosaico. Como aponta Daniels, é um local de encontro como se estivesse sendo visto "do andar de cima do ônibus" (Daniels, 2006: 41). Assim, “(...) enquanto Penny Lane oferece um retrato geograficamente acurado de um lugar ordinário, Strawberry Fields Forever produz um novo lugar, ainda assim ligado à imagem das crianças órfãs residentes no lugar de fato" (Kruse II, 2005).

Quando voltamos nossos ouvidos para certos aspectos composicionais, o quadro ganha novas formas. Alan Pollack salienta que, por mais experimental que aparente ser - progressão harmônica que oscila entre a "claridade tonal" e progressões ambíguas, mudança de métrica de $4 / 4$ para $6 / 8$ apenas no trecho final do refrão -, Strawberry Fields adota a forma típica de uma balada folk (a não ser no fim), começando com o refrão e alternado para as estrofes, sem qualquer ponte ou solo (Pollack, 1995: 398). Já Penny Lane apresenta uma mescla de estilos difícil de ser classificada, combinando elementos "clássicos" e "populares", passagens harmônicas inusitadas que remetem ao jazz e ao impressionismo francês e co-habitam com clichês de canções da virada da década de 1950 para a de 1960, como o de repetir o coro final mudando para um tom mais agudo (Pollack, 1995: 392).

Há também o solo de trompete piccolo, instrumento do período barro$\mathrm{co}^{15}$ que Paul viu ser tocado por David Mason numa performance televisionada do $2^{\circ}$ Concerto de Brandenburgo, de Bach. Ditado por McCartney e escrito na pauta por Martin para que o próprio Mason executasse, combinava o timbre que remetia ao "antigo/erudito" com a melodia mais próxima do "pastoral", mas assume um contraste com o resto do arranjo, acrescentando um teor irônico (Pollack, 1995: 393). Se parece mais convencional na superfície, a canção de Paul principiou de forma mais experimental que a de John, já que a trilha-base ${ }^{16}$ que produziu 
sozinho tinha três pianos gravados em canais diferentes e sobrepostos (um com velocidade alterada, um amplificado e reverberado, outro inalterado), mais órgão e efeitos de percussão (Kozzin, 1995: 134).

Para retratar um lugar real, McCartney cria uma narrativa ficcional, bastante detalhista, de modo a produzir um efeito de verdade. Os detalhes, como recursos mnemônicos, promovem a rememoração, ao mesmo tempo que enfatizam o sentimento de pertencimento ao lugar para os que identificam as referências (Batna, 2010: 51). A fotografia é um elemento constante na letra, como um signo que atesta o registro fiel do cotidiano, ao mesmo tempo em que retém uma "aura" do passado (nos anos 1960 há uma obsessão por fotografias antigas) e assume o caráter de "representação gráfica da alteridade" (Samel,1994: 322). O barbeiro mostra fotografias de "cada cabeça que já teve o prazer de conhecer"; o bombeiro guarda no bolso "um retrato da Rainha".

A ação se dá no "agora", com verbos usados no tempo presente, mas ao mesmo tempo se apresenta como um registro preservado na memória, um "instantâneo" que foi literalmente capturado através dos sentidos durante o deslocamento do narrador pelo espaço urbano (expressado musicalmente no pulso rítmico próximo da marcha), algo que o refrão resume com perfeição: "Penny Lane está em meus ouvidos, e em meus olhos/molhada sob os céus azuis suburbanos". Esse mesmo procedimento pode ser identificado na gravação pelo uso de sons que integram a paisagem sonora ${ }^{17}$ da rua movimentada, percebida realística ou metaforicamente: o sino que toca quando o bombeiro é mencionado, apitos, metais que emulam buzinas de carros, pratos indicando a queda da chuva, percussão de timbre metálico, flautas que soam como conversa ou como os risos das crianças pelas costas do bancário. A sucessão de sonoridades e climas (incluindo referências a variações do tempo e das estações do ano) indica que é precisa a observação de que a cena, aparentemente descrita de forma naturalista, é de fato caleidoscópica (MacDonald, 1995: 179).

Lennon, por sua vez, evita uma narrativa descritiva e adota um ponto de vista psicológico que problematiza a percepção - "nada é real"; "com os olhos fechados"; "confundindo tudo que você vê" - intercalado com sua experiência pessoal, incluindo aí reflexões sobre seu jeito diferente - "moderno"; "alucinado"; "devo ser um louco ou um gênio" - de ver o mundo, que ele mesmo considerava ter iniciado quando ainda era criança ${ }^{18}$ : "ninguém, penso eu, está na minha árvore/quer dizer, ela deve ser alta ou baixa”. Seguindo as observações de MacDonald (1995: 172-173) sobre as referências simbólicas ao imaginário infantil (jogos, esconde-esconde, subir em árvores), Barna (2010: 50) considera que o lugar Strawberry Field permite evocar nostalgicamente a inocência e a liberdade da infância, que são suprimidas na vida adulta. Porém, ao ressaltar a fabricação de uma imagem idílica, a autora perde de vista não apenas as atribulações da in- 
fância de Lennon, mas também a estética vacilante e variante que marca todo o processo de gravação, produzindo uma paisagem ambígua.

No clima de indecisão e incerteza criado em letra e música, é preferível considerar que as reminiscências de infância, insinuadas no cenário que ecoa a paisagem pastoral e os jardins secretos da literatura infantil, servem apenas como ponto de referência de um deslocamento para outro lugar ("deixe-me levá-lo rumo abaixo/ porque estou indo para"), fazendo surgir um espaço para a imaginação, que favorece uma multiplicidade de leituras e se entretece com as experiências dos ouvintes (Kruse II, 2005). Para John, essa possibilidade era um dado incorporado ao próprio ato de compor, constatação sintetizada na frase em que afirmou ter usado o nome do orfanato como "uma imagem": um lugar imaginário em que não há "nada com que se preocupar", e "está ficando difícil ser alguém", mas, ao mesmo tempo, "tudo se resolve" e "não está tão mal".

Esse lugar é construído a partir de fragmentos do discurso coloquial empregado em diálogos - "eu acho", "você sabe" -, misturados com referências culturais tão diversas quanto o slogan psicodélico de Timothy Leary - "tune in" ("entrar em sintonia") e o clássico da canção norte-americana Summertime (George \& Ira Gershwin) - "living is easy" ("viver é fácil"). Se a letra apresenta forma de sonho, a referência que oferece um modelo para a estrutura da canção é As aventuras de Alice no país das maravilhas (1865), de Lewis Carroll, livro que fascinava Lennon desde menino e se tornara um texto canônico da estética psicodélica da época. Em seu sonho, Alice segue o Coelho Branco, descendo por sua toca em direção a um mundo subterrâneo (underground!), povoado de imagens "surrealistas”, acontecimentos extraordinários e diálogos nonsense (Daniels, 2006: 40).

Outras canções, compostas no mesmo período, foram fortemente influenciadas pela imagética e jogos de palavras das obras de Carroll, bem como de seu contemporâneo Edward Lear, autor de Nonsense Verses (Lucy in the Sky with Diamonds ${ }^{19}$ I am the Walrus $^{20}$ ), mas também reverberam o vernáculo liverpudliano do "cético suburbano", do humor proletário dos "humoristas das docas", bem como de grupos cômicos dos programas de rádio e televisão (que John assistia bastante em sua fase "caseira"), como os Goons. Vale acrescentar que, no início da carreira, George Martin produziu discos de humoristas para os quais criava o que chamou de sound pictures, "quadros sonoros" em que a música construía uma ambientação para as cenas cômicas.

Martin aprimorou, sem dúvida, essa técnica, produzindo os discos dos Beatles, e nas gravações de que tratamos aqui ela se tornara indispensável. Um exemplo é Being for the benefit of Mr. Kite, ${ }^{21}$ composta por Lennon como uma "cópia direta" de um cartaz de um circo do período vitoriano (do tipo que se apreciava nas cidades do norte) que comprara num antiquário. Em meio às atrações, cavalos amestrados, família de trapezistas, anéis de fogo e saltos mortais, pode-se 
literalmente "sentir o cheiro do picadeiro", efeito criado com a ajuda da montagem aleatória de pedaços de uma fita gravada por Martin tocando órgão Hammond, a partir de partituras antigas, alterados para que soassem como um velho órgão a vapor. Richard Leppert destaca que a música, enquanto experiência e performance, instaura, a partir de sua relação com o corpo, uma visualidade: “(...) quando nós consumimos música, consumimos também uma imagem - corporificada, ativa, situada, tudo isso mediando significados musicais" (Leppert, 1995: 518). Em um trabalho anterior, tendo justamente em mente a expressão usada por Martin, considerei que "(...) o arranjo musical instaura um quadro sonoro, com paisagens e referências visuais sugeridas a partir de sonoridades, observáveis em seus aspectos timbrísticos e performáticos" (Garcia, 2003: 124-125).

Como a menina Alice, o ouvinte de Strawberry Fields é conduzido por um país das maravilhas sonoro, povoado por estranhezas, muitas delas produzidas com técnicas de estúdio, ${ }^{22}$ desenvolvidas para os Beatles pelos engenheiros de som de Abbey Road, como a duplicação artificial (ADT) da voz, variação da velocidade do tape e gravações trocadas de trás para frente (no caso, pratos). Enquanto a canção avança, o arranjo se adensa, o movimento de descida se intensifica e a instrumentação torna-se mais complexa, deslocando-se do cenário pastoral da introdução tocada no mellotron, ${ }^{23} \mathrm{com}$ timbre de sopro e andamento mais leve, passando para pesada orquestração "pseudo clássica" e chegando à fanfarra final da bateria de Ringo, encarnando os tambores marciais da banda do "Sargento Pimenta".

O tempero do swordmandel, uma espécie de harpa indiana, completa a paleta de sonoridades inusitadas. Essa rica variação de texturas do arranjo foi produzida de modo improvável, definitivamente inovador: o terço inicial de uma tomada da versão com arranjo "nostálgico" (take 7, gravada em A [lá]) foi acelerada, sendo justaposta (exatamente no primeiro minuto da gravação) aos outros $2 / 3$ de tomada com arranjo "contemporâneo" (take 26, em B [si]), que teve sua velocidade reduzida, para que, com a dose certa de sorte, no ponto de junção, as duas tomadas se aproximassem afinadas no tom $\mathrm{Bb}$ [si bemol]. Essa variação de climas sublinha bem o nonsense da letra, e uma dose extra de incerteza é acrescida pelo falso fade out ${ }^{24}$ final (Pollack, 1995: 396).

A análise musicológica de Pollack apresenta como chave de leitura para as duas canções a mistura entre o familiar e o surpreendente. De fato, ele estende essa observação para a obra dos Beatles como um todo, chamando a atenção para sua grande capacidade e interesse por "flexionar estilos", ressaltando como isso é particularmente evidente em Sgt. Pepper's (Pollack, 1995: 399). Mantendo-se fiel à combinação de nostalgia e inovação, o disco traz elementos que permitem reconhecer um conceito que, segundo George Martin, havia sido definido por Strawberry Fields. Ele, inclusive, lamentaria posterior- 
mente não tê-la lançado (juntamente com seu par, Penny Lane) no LP, já que as exigências do mercado acabaram obrigando seu lançamento em compacto, e repetir as faixas no álbum seguinte era altamente indesejável para os padrões da indústria fonográfica britânica da época. Ainda mais levando-se em conta que $o$ assunto recorrente na imprensa especializada em música popular nos meses que antecederam o lançamento de Sgt. Pepper's era a demora das gravações e seu alto custo, problemas agravados pelo fato dos Beatles terem interrompido suas apresentações ao vivo.

Como aponta Marcos Napolitano, a música popular urbana apropria-se de elementos da música erudita, folclórica e do cancioneiro de domínio público, produzindo uma forma adaptada às necessidades de entretenimento das novas camadas urbanas (Napolitano, 2002: 11). Na entrada do século XX, os sujeitos que faziam música popular experimentavam os dilemas da modernidade de perto, na medida em que sua própria linguagem musical era uma expressão inequívoca das suas contradições: "A música popular nasceu bastarda e rejeitada por todos os campos que lhe emprestaram seus elementos formais (...)" (Napolitano, 2002: 15).

Para os adeptos da música erudita, representava o êxito do compositor medíocre que recorria a fórmulas simplórias e redundantes, de gosto duvidoso. Para os folcloristas, violava a "pureza" das formas rurais e anônimas, legítimas expressões da "alma do povo". Nesse cenário, impactadas pelas forças de mercado, as fronteiras entre discursos musicais distintos tornaram-se mais móveis, seja na produção, na distribuição ou no consumo (Frith, 1996: 45). Através dos meios de comunicação massivos veio a ocorrer o que García Canclini identificou como fim do colecionismo, pois "as tecnologias de reprodução permitem a cada um montar em sua casa um repertório de discos e fitas que combinam o culto com o popular, incluindo aqueles que já fazem isso na estrutura das obras (...)" (García Canclini, 1997: 304).

Esse gesto "descolecionador" encontra-se no cerne do que os Beatles estavam buscando. Em depoimento ao jornal underground International Times (que Paul ajudara a criar), George Harrison dizia que os Beatles não deveriam mais se limitar ao pop, achando inclusive que “(...) a gente se conteve demais em coisas como 'Strawberry Fields' (...) acho que provamos que a música eletrônica pode se misturar com a música 'pop', e provaremos que música indiana, eletrônica e 'pop' podem andar juntas" (Heylin, 2007: 138). Ele acrescentaria mais um ingrediente ao caldeirão de sons, ao propor unir música de concerto e instrumentos indianos na canção Within you, Without you.

Essa atitude tornara-se possível num contexto em que os Beatles, abandonando as excursões, mudaram seus métodos de trabalho, levando canções apenas esboçadas para construí-las no estúdio e improvisando durante horas, dei- 
xando os técnicos exaustos e entediados. George Martin declarou que a parte mais difícil do LP foi começar a gravar às sete da noite e trabalhar até as três (Heylin, 2007: 100). Seu papel como produtor mudara: deixava de dar as direções para concretizar as ideias dos Beatles, por mais mirabolantes que fossem. Mais importante do que ter acesso à tecnologia de gravação era ter alguém que pudesse conduzi-la no rumo desejado. Mas que rumo? Em direção ao passado suburbano ou à última moda de Londres?

Falando em moda, Samuel localiza na Swinging London de meados dos anos 1960 o fenômeno do retro-chique, ou "indústria da nostalgia", em que a tecnologia recente é aplicada aos produtos de modo a obter uma estética que remete ao antigo (Samuel, 1994: 83), influenciando do vestuário às capas de disco. Mesmo sendo uma forma de revival, tem um caráter paródico:

Ao contrário do restauracionismo e do conservantismo (...), o retro-chique é indiferente ao culto da autenticidade. Ele não se sente obrigado a permanecer fiel ao período (...) borra a distinção entre originais e reciclados (...) abole as diferenças de categorização entre passado e presente, abrindo um trânsito de mão dupla entre eles (Samuel, 1994: 112-113)

Há dois pontos de contato com o caso que estamos investigando, musical e visual. Musical porque, como vimos, os arranjos das duas canções atravessam gêneros e temporalidades diferentes. Visual porque é significativo que tenham sido produzidos e lançados filmes promocionais para as duas canções, uma vez que o mesmo autor identifica nesse mesmo período o início do predomínio do "visual" sobre o "auditivo" na cultura britânica (Samuel, 1994: 337-339). Ironicamente, não há qualquer cena dos Beatles em Liverpool. No filme de Strawberry Fields a cidade sequer aparece, pois a única locação é um morro, em que eles estão junto a um piano de armário sobre o qual está um tear, cujos fios se entendem até um carvalho. No de Penny Lane, externas do local mostram placas e ônibus estampando o nome do logradouro, intercaladas com cenas dos Beatles atravessando Londres a cavalo, vestindo casacos de caça à raposa, em direção a um parque onde será servida uma refeição aristocrática (Daniels, 2006: 42).

A montagem segue, nos dois filmes, o ritmo das canções e consegue traduzir as técnicas usadas nas gravações, especialmente na cena em que Paul se move de trás para frente e "cai para cima" de um galho da árvore. Esteticamente, o primeiro filme é bem mais vanguardista, dando uma pista sobre a diferença na recepção de cada lado do compacto. As sequências finais, por sua vez, evidenci- 
am - no improviso iconoclasta, com um quê de nonsense e sem qualquer agressividade explícita - sua semelhança no confronto entre o convencional e o transgressor: em uma cena, após derramar tintas no tear, eles derrubam o piano; na outra, no momento em que vão ser servidos, derrubam a mesa.

Qualquer carga de nostalgia e localismo que se possa reconhecer nos Beatles precisa vir acompanhada do riso irônico, traço marcante da personalidade de todos eles. Elemento subestimado quando Barna (2010) aborda suas canções, o que é curioso consideradas as referências que faz ao dialogismo bakhtiniano. Transgressão que voltava também contra sua aparência pop. Desde 1966 vinham abandonando os ternos e cortes de cabelo padronizados, e depois que encerraram a última turnê Lennon passou a usar óculos de "vovô" (aros circulares) e todos adotaram roupas psicodélicas e bigodes, que passariam depois a ser vistos nos chamados "heróis da classe trabalhadora" (Samuel, 1994: 97). Lay-out propositalmente datado que aparece na capa do compacto, que traz ainda estampada uma moldura em torno da foto, de modo a imitar um porta-retratos antigo. $\mathrm{O}$ visual combinava com os uniformes de regimento eduardiano usados depois na capa de Sgt. Pepper's.

Dialeticamente, se toda essa encenação da mudança mostra os Beatles afastando-se de suas personagens de estrelas do pop, era justamente seu êxito até aquele momento que lhes dava respaldo diante da EMI para "ir longe". Encarando de forma mais abstrata, trata-se de metamorfose: morte e nascimento, réquiem e fanfarra, como explicou um crítico quando o disco saiu, assegurando ainda que as canções do compacto "foram prévias perfeitas" (Heylin, 2007:171). Harrison disse ao repórter da revista Life que acompanhava uma noite de gravações:

Acabamos de descobrir o que podemos fazer como músicos. Quais fronteiras podemos cruzar. Não faz mais tanta diferença se estamos em primeiro lugar nas paradas. Tudo bem se as pessoas não gostarem de nós. Só não tentem nos podar (Heylin, 2007: 135)

McCartney faria coro, afirmando que não se abrir para coisas novas poderia significar sucesso e fracasso ao mesmo tempo. Ele disse a Thomas Thompson, da Life: “(...) vamos perder alguns fãs. Nós os perdemos em Liverpool quando trocamos nossas jaquetas de couro por ternos (...) chegamos a um ponto onde não existem barreiras (...)" (Heylin, 2007: 135). Mas, hesitante, também demonstrava estar preocupado em evitar "ir longe demais" e distanciar-se dos fãs, o que explica a ousadia de Penny Lane ser dosada por uma melodia cantarolável. Era a árdua busca do equilíbrio entre pop e progresso. 
Creio que é possível concluir que a criação dos músicos populares confere significado a suas relações com o espaço urbano, seja o da cidade natal ou o da capital em que então residiam. Para Lennon, vivendo entre o que considerava uma vida suburbana restritiva e o anseio de romper com ela, o lugar da infância é apropriado como imagem, campo de sonho transfigurado em passagem para outro lugar, em que a realidade percebida e a validade das convenções podem ser questionadas. McCartney, lançando mão de detalhes inventados, traça o panorama (sur)realista de um lugar da cidade povoado por vários personagens que interagem na concretude de suas ações - "o barbeiro faz a barba de outro freguês"; "vemos o bancário sentado esperando por um corte"; "o bombeiro entra fugindo da chuva" -, percebendo o extraordinário no corriqueiro: "muito estranho", comentário literal e musical.

No próprio lugar, a canção “(...) re-contextualiza o mundano e torna visíveis os detalhes subestimados da vida cotidiana" (Kruse II, 2005). Mas a espontaneidade desse mundo suburbano é posta em dúvida quando notamos que a bela enfermeira que vende papoulas "atrás do abrigo, no meio da rotatória" sente-se "como se estivesse numa peça". E "ela está, de qualquer modo", na peça da nostalgia idealizada de seu compositor. Circulando pela cena underground londrina, Paul refinava um modo de reapresentar o passado e a vida suburbana, que, na sua teatralidade, eram simultaneamente cômicos e belos, humor que pode bem ser tomado como ressonância das ruas de Liverpool.

Estudando suas práticas descolecionadoras, é possível entender o modo com que seu deslocamento no espaço urbano transmuta os caminhos de sua criação musical. Estudando os detalhes das gravações, tomando como chave a elaboração dos quadros sonoros, é possível entender como a música popular (re)cria uma paisagem. Constroem-se lugares diferentes, as duas canções lançam mão de material semelhante: a ambiguidade característica da elaboração formal, entre o familiar e o inovador; a mistura de gêneros musicais por apropriação, irônica sem ser depreciadora; o convívio en tre referências sonoras ao passado e o emprego de técnicas de gravação que lhes confere outros significados; uma proposta estética que borra as fronteiras entre arte e $p o p$.

Ao examinar as memórias e os trajetos dos Beatles, constatamos que a experiência urbana afeta suas criações nos cruzamentos entre o provinciano e o cosmopolita, entre a nostalgia e a vanguarda, entre o sonho e a realidade. Ao adentrar o jardim de morangos e caminhar pela alameda do centavo, de olhos e ouvidos abertos, encontramos um lugar entre Liverpool e Londres, entre a tradução em palavras e sons das recordações sobre o norte e a infância e a absorção dos comportamentos de vanguarda em uma busca constante por descobertas musicais. 
1. Lennon, John \& McCartney, Paul. The Beatles. Strawberry Fields Forever/Penny Lane EMI, 1967. Posteriormente, a EMI incorporou as duas faixas (e mais outras 3) ao EP da trilha original do filme Magical Mystery Tour (1967) para o LP lançado pela Capital, braço norte-americano da gravadora, adotando definitivamente este formato quando relançou a obra completa dos Beatles em CD.

2. Nos compactos, a canção de maior apelo comercial vinha no lado $\mathrm{A}$, deixando $\mathrm{B}$ para a gravação de menor potencial. Os Beatles, rompendo os padrões da indústria fonográfica, passaram a lançar compactos com canções que eram consideradas equivalentes.

3. Embora assinassem sempre juntos, muitas canções de Lennon e McCartney não foram compostas em parceria, como eles próprios revelaram em várias entrevistas.

4. Cott, Jonathan. John Lennon - entrevista. Rolling Stone Magazine, 23/11/1968. $<$ http://www.beatlelinks.net/forums/ showthread.php? $\mathrm{t}=17259>$, consultado em 08/03/2008.

5. Lennon, John \& McCartney, Paul. The Beatles. LP Rubber Soul, EMI, 1965.

6. Em Liverpool a denominação é também aplicada ao entorno, envolvendo área residencial e comercial.

7. Uma libra esterlina é dividida em 100 pence (do singular penny).

8. Todo o processo de composição e construção do arranjo pode ser acompanhado em discos "piratas", que incluem as demos gravadas por John na Espanha e em sua casa em Kenwood, bem como as sessões de gravação da EMI. Aqui foi utilizado John
Lennon/The Beatles. It's not too bad. Peg Boy, 1997. As traduções são minhas.

9. Paul e Linda McCartney - entrevista. Playboy Magazine, 1984. < http://www. geocities.com/ beatleboy $1 / \mathrm{dbpm}$.int 2 .ht ml $>$ Consultado em 30/07/2008.

10. Harrison, George. The Beatles. LP Yellow Submarine, EMI, 1969.

11. Endereço dos estúdios da EMI onde os Beatles gravaram a maior parte de sua obra.

12. Sheff, David. John Lennon and Yoko Ono-entrevista. Playboy Magazine, 1980.

\section{Idem.}

14. Ao ressaltar o papel desempenhado pela música no revivalismo, Samuel cita como exemplo a retomada de instrumentos e peças originais do início da música barroca (Samuel, 1994: 23).

15. Numa prática que se tornaria recorrente, os quatro canais da gravação foram comprimidos em um único canal para ganhar espaço na fita, pois os estúdios da EMI em Abbey Road ainda utilizavam mesa com quatro canais, enquanto nos EUA já eram operadas mesas com oito.

16. O conceito de paisagem sonora (soundscape) foi proposto pelo musicólogo R. Murray Schaffer, para caracterizar qualquer campo de estudo acústico, configurado por eventos ouvidos, não necessariamente considerados como música (Schaffer, 2001: 23-24).

17. Sheff, David, op.cit.

18. Lennon, John \& McCartney, Paul. The Beatles. LP Sgt. Pepper's Lonely Hearts Club Band. EMI, 1967. A canção chegou a ser proibida em algumas rádios pela 
referência ao LSD em suas iniciais, mas, segundo seus compositores, era inspirada em um inocente desenho infantil feito pelo filho de Lennon.

19. Lennon, John \& McCartney, Paul. The Beatles. EP Magical Mystery Tour. EMI, 1967 (ver nota 1). Há uma parte de Alice através do espelho intitulada justamente " $\mathrm{O}$ Carpinteiro e a Morsa" (walrus).

20. Lennon, John \& McCartney, Paul. The Beatles. LP Sgt. Pepper's Lonely Hearts Club Band. EMI, 1967.

21. O estúdio tornara-se um novo instrumento, uma vez que a aplicação da tecnologia de gravação em múltiplos canais, utilizando simultaneamente as diferentes

\section{Referências bibliográficas}

BARNA, Emilia. 'There are places I'll remember ...': A Sense of Past and Locality in the Songs of the Beatles and the Kinks. Sounds of the Overground: Selected papers from a postgraduate colloquium on ubiquitous music and music in everyday life. Edited by Nedim Hassan and Holly Tessler. Turku, Finland: International Institute for Popular Culture, 2010, p. 49-57. < http://iipc.utu.fi/overground/ barna.pdf $>$, acessado em 31/03/2011.

BASTOS, Rafael Menezes. A "origem do samba" como invenção do Brasil (Por que as canções tem música?). Revista Brasileira de Ciências Sociais, ${ }^{\circ}$ 31, ano 11, jun. 1996, p. 156-177.

COHEN, Sarah. Identity, place and the 'Liverpool sound'. In: STOKES, Martin (edit.). Ethnicity, identity and music: the musical construction of place. Oxford: Berg Publishers, 1994. pistas da fita magnética, permitiu montagens, edições, acelerações e toda uma série de procedimentos para alterar de diversas formas o som gravado. Para uma discussão teórica sobre música e tecnologia de gravação, ver Frith, 1996: 226245.

22. Rudimentar teclado eletrônico que usava fitas previamente gravadas com sons de alguns instrumentos.

23. Encerramento de uma faixa através da redução gradual do volume, sem que os músicos parem de tocar

24. Harrison, George. The Beatles. LP Sgt. Pepper's Lonely Hearts Club Band. EMI, 1967.

CONNELL, John \& GIBSON, Chris. Sound tracks: popular music, identity, and place. Londres: Routledge, 2002.

DANIELS, Stephen. Suburban pastoral: Strawberry Fields forever and Sixties memory. Cultural Geographies, n 13, 2006, p. 28-54.

FRITH, Simon. Performing rites: on the value of popular music. Cambridge, Massachusetts: Harvard University Press, 1996.

KRUSE II, Robert J. The Beatles as Place Makers: Narrated Landscapes in Liverpool, England. Fournal of Cultural Geography, n 22.2, 2005. < http://www. questia.com/PM.qst? $\mathrm{a}=\mathrm{o} \& \mathrm{~d}=501133431$ $1>$ acessado em 26/07/2008.

GARCIA, Luiz Henrique A. O modal e a modinha: transações musicais brasileiras 
através da iconografia. Cronos. Pedro Leopoldo, v. 7, 2003, p. 123-134.

\begin{abstract}
- Na esquina do mundo: trocas culturais na música popular brasileira através da obra do Clube da Esquina (1960-1980). Tese (Doutorado em História). Faculdade de Filosofia e Ciências Humanas/Universidade Federal de Minas Geais. Belo Horizonte, 2007
\end{abstract}

GARCÍA CANCLINI, Néstor. Culturas híbridas. São Paulo: Editora USP, 1997.

HEYLIN, Clinton. Sgt. Pepper's Lonely Hearts Club Band: um ano na vida dos Beatles e amigos. São Paulo: Conrad, 2007.

HOBSBAWM, Eric J. História social do jazz. Rio de Janeiro: Paz e Terra, 1991.

KOZINN, Allan. The Beatles. Londres: Phaidon, 1995.

LEPPERT, Richard. Social order and the domestic consumption of music. In: BERMINGHAM, Ann \& BREWER, John. The consumption of culture 1600-1800. Londres: Routledge, 1995.
MACDONALD, Ian. Revolution in the Head: The Beatles' Records and the Sixties. Nova York: Owl Books, 1995.

NAPOLITANO, Marcos. História e música. Belo Horizonte: Autêntica, 2002.

NEGUS, KEITH. Popular music in theory. Middletown: Wesleyan University Press, 1996.

POLLACK, Alan W. Notes on... Series, 1995. The 'Official' rec.music.beatles Home Page < http://www.recmusicbeatles.com>, acessado em 23/07/2008.

RAPHAEL, Samuel. Theatres of memory vol 1: Past and present in contemporary culture. Londres: Verso, 1994.

SCHAFER, R. M. A afinação do mundo. São Paulo: Editora Unesp, 2001.

STOKES, Martin. Introduction In: STOKES, Martin (edit.). Ethnicity, identity and music: the musical construction of place. Oxford: Berg Publishers, 1994.

\section{Resumo}

Meu propósito é investigar como a música popular, através de trocas culturais que marcam a construção de identidades atribuídas a grupos e lugares, define vínculos e fronteiras no tecido urbano, ao mesmo tempo em que evidencia as trajetórias traçadas pelos músicos que o atravessam. Para tanto, optei pelo estudo formal e contextual de Strawberry Fields Forever e Penny Lane, canções dos Beatles que produzem sentidos sobre "lugares" e que congregaram memórias e identidades construídas em sua experiência como citadinos no deslocamento desde seu passado em Liverpool ao presente de então em Londres.

Palavras-chave: música popular; espaço urbano; história; memória.

\section{Abstract}

My purpose is to investigate how popular music, through cultural exchanges that mark the construction of identities assigned to groups and places, defines 
connections and boundaries in the urban tissue while showing the paths traced by the musicians who pass through it. To that end, I opted for the formal and contextual study of Strawberry Fields Forever and Penny Lane, Beatles' songs which produce meanings about "places" that gathered memories and identities built on their experience as city dwellers moving from their past in Liverpool to their present (in that time) in London. Keywords: popular music; urban space; history; memory.

\section{Résumé}

Mon but est d'étudier comment la musique populaire, par des échanges culturels qui marquent la construction des identités attribuées à des groupes et des lieux, définit les liens et limites dans le tissu urbain tout en montrant les chemins tracés par les musiciens qui passent à travers. À cette fin, j'ai opté pour l'étude formelle et contextuelle de deux chansons des Beatles, Strawberry Fields Forever et Penny Lane, productrices des significations sur "lieux" et qui ont rassemblé des mémoires et des identités basées sur leur expérience comme citadins dans le déplacement, dès leur passé à Liverpool jusqu'à leur présent (à ce moment-là) à Londres.

Mots-clés: musique populaire; espace urbain; histoire; mémoire. 